\title{
CARRERA DE PEDAgOGíA A DISTANCIA: OBSTÁCULOS EN LA PROPOSICIÓN DE LA CARRERA COMO FORMACIÓN INICIAL
}

\author{
(DISTANCE LEARNING COURSE OF PEDAGOGY: PREDICAMENTS IN THE COURSE \\ PROPOSITION AS AN INITIAL GRADUATION)
}

\author{
Norinês Panicacci Bahia \\ Marília Claret Geraes Duran \\ Universidade Metodista de São Paulo (Brasil)
}

\section{RESUMO}

Este texto apresenta os resultados de uma pesquisa que realizou um estudo de caso, numa abordagem longitudinal, considerando as turmas de um curso de pedagogia na modalidade a distância, de uma instituição de ensino superior particular, do município de São Bernardo do Campo, estado de São Paulo, que teve por objetivo traçar o perfil dos alunos e analisar as opiniões e percepções destes sobre o próprio curso. Este texto aprofunda as reflexões acerca dos avanços e retrocessos nas discussões sobre a legitimidade de cursos de formação inicial de professores nesta modalidade, que tem suscitado sentimentos percebidos pelos alunos como de discriminação, além da insegurança sobre a validade do curso que frequentam. Para a coleta de dados, foram encaminhados 325 questionários para os 27 polos do curso, localizados em diversas cidades do estado de São Paulo e estados do Brasil considerando uma amostra de alunos dos seis períodos do curso. Obtivemos o retorno de 238 questionários respondidos por alunos que espontaneamente decidiram colaborar com a pesquisa. O questionário encaminhado possui questões para a coleta de dados sobre o perfil e para informações sobre as opiniões e percepções dos alunos sobre o próprio curso. A partir dos dados coletados e das análises realizadas podemos afirmar que a maioria dos alunos pertence a uma faixa etária mais velha (25-30 anos), é casada, possui uma renda familiar baixa, os pais têm escolaridade mínima, possui computador conectado à internet e trabalha na área da educação - e esse dado pode significar a busca pelo curso de pedagogia como formação continuada. De um modo geral, expressam a satisfação com o curso na modalidade a distância, mas evidenciam sentimentos negativos, de não aceitação e de preconceito, que são percebidos na relação com familiares e amigos, e isso parece denotar que a modalidade seja considerada de menor prestígio.

Palavras-chave: curso de pedagogia a distância; formação inicial; perfil dos alunos; discriminação. 


\begin{abstract}
This paper discusses the results of a longitudinal case study designed to construct a profile of distance undergraduate students and to analyze their opinions and insights concerning their study of pedagogy at a private university, in the city of São Bernardo do Campo, São Paulo, Brazil. The article discusses the legitimacy of undergraduate distance teacher education courses and students' feelings of discrimination and insecurity about the validity of such courses. Questionnaires were distributed to 325 students of the six grades in 27 different distance learning centers located in various cities of the state of São Paulo and around Brazil. Based on the data supplied by the 238 students who responded to the questionnaire, the profile of the respondents was as follows: 25-35 years old, married, low-salaried, parents of low formal education attainment, connected to the Internet and employed in education-related jobs. The data also showed that those who worked in education-related jobs preferred to enroll in a pedagogy course as continuing education. Although students were generally satisfied with the course, they also reported negative treatment of non-acceptance and discrimination, usually from their relatives and friends, revealing that this type of teacher education course probably still enjoys lower prestige that residential teacher education.
\end{abstract}

Keywords: distance learning pedagogy course, undergraduate courses, students' profile, discrimination.

A proposição e disseminação de cursos de graduação a distância no contexto educacional brasileiro, já não é mais nenhuma novidade - basta observar os expressivos números estatísticos sobre o crescimento desta modalidade: "o número de cursos de graduação em EAD no país cresceu 571\% entre 2003 e 2006, e o número de matrículas 315\% no mesmo período" (Sánchez, 2008, p. 17).

O discurso em defesa destes cursos assegura a oportunidade do acesso ao ensino superior de grande parte da população brasileira que estava excluída deste nível de ensino, quer pelo baixo custo dos cursos a distância, quer pela instalação de polos presenciais de instituições de ensino superior em diversas regiões do país, que não as possuíam.

Apesar da legislação específica e das políticas oficiais para a educação a distância, lidamos ainda com avanços e retrocessos nas discussões sobre a legitimidade de cursos de formação inicial de professores nesta modalidade, especialmente o curso de pedagogia - e este foi o foco principal para o desenvolvimento da investigação que ora apresentamos, que priorizou as reflexões acerca das opiniões e percepções dos alunos sobre o próprio curso; sobre as implicações diante das incertezas da legitimidade do curso, que suscitam sentimentos de preconceito; e das contradições entre o reconhecimento e autorização dos cursos, pelo governo federal, e as posições contrárias das entidades de classes e alguns estudos que criticam a formação inicial de professores na modalidade a distância. 
Dados atuais, de 2010, apontam que somente o Sistema Universidade Aberta do Brasil ${ }^{1}$ possui, na modalidade a distância, 307 cursos de licenciatura, 50 cursos de extensão, 78 bacharelados, 14 cursos para tecnólogos, 266 especializações e 167 de aperfeiçoamento, em várias áreas e, ainda, em relação às instituições privadas, conforme dados do Censo da Educação Superior de 2008, 115 instituições ofereceram 647 cursos de graduação atendendo 727.961 alunos e, destes, 341.118 alunos, eram de cursos de licenciatura, na modalidade a distância (Sommer, 2010, p. 20).

Assim, é importante considerarmos os impactos que se anunciam na área de formação de professores nesta modalidade - na capacitação dos professores que irão formar os futuros professores e no próprio formando - todos, sujeitos de um momento histórico marcado por uma inovação na área educacional que, desejamos, possa dar conta de contribuir efetivamente com a melhoria da qualidade da educação brasileira.

\section{O CONTEXTO E OS CAMINHOS DA PESQUISA}

Esta pesquisa se inseriu nos estudos e pesquisas do Grupo de Estudos e Pesquisas sobre Educação a Distância - GEPEAD, do Programa de Pós-Graduação: Mestrado em Educação, de uma Instituição de Ensino Superior, e foi realizada no período de 2008-2010, sob a coordenação das autoras. O grupo é devidamente cadastrado no Diretório dos Grupos de Pesquisas no Brasil - CNPq, desde novembro/2006 e promove investigações sobre a educação a distância, especialmente sobre a formação inicial e continuada de professores, nesta modalidade.

A pesquisa se realizou considerando um Curso de Pedagogia, oferecido por uma instituição de ensino superior particular, do município de São Bernardo do Campo, estado de São Paulo, que oferece cursos de graduação na modalidade a distância, desde agosto de 2006.

O que nos pareceu importante investigar refere-se aos indícios de não aceitação da formação inicial de professores na modalidade a distância, para atuarem na educação infantil e nas séries iniciais do ensino fundamental, tendo em vista as discussões e debates atuais sobre se a modalidade deveria ocorrer apenas como formação continuada. Isso vem provocando alguns desdobramentos, como por exemplo, as dificuldades que os alunos encontram para a realização de estágios, ou mesmo para se inscreverem em alguns concursos públicos para a docência na educação infantil e no ensino fundamental, concursos que vetam a participação de profissionais 
formados em cursos a distância - estas dificuldades podem ser traduzidas como um preconceito em relação a esta modalidade de formação.

A relevância da pesquisa se expressa pela possibilidade de problematizarmos a própria concepção de formação de professores nesta modalidade, tanto numa perspectiva mais teórica epistemológica, considerando estudos e pesquisas realizadas sobre processos formativos em EAD, conforme Barreto et alli (2006); Valente e Almeida (2007); Duran (2008); Gatti e Barreto (2009); Bahia e Duran (2009), como em discussões mais pontuais, que recomendam a modalidade como formação continuada, e não inicial, conforme Scheibe (2006); Giolo (2008); Sommer (2010), o Boletim ANFOPE - Associação Nacional pela Formação dos Profissionais da Educação (2007) e o Documento Final da última CONAE - Conferência Nacional da Educação (2010).

Do ponto de vista acadêmico, sua relevância se expressa na possibilidade de respondermos a duas questões fundamentais: O que pode e deve ser hoje a modalidade a distância em cursos de formação de professores? A que necessidades sociais ela deve responder? E, do ponto de vista de sua relevância política, considerando as possibilidades de os cursos de pedagogia a distância serem oferecidos, a partir do cumprimento das diretrizes e normas oficiais que regulam a modalidade.

A opção metodológica para a investigação foi a de realizar um estudo de caso de cunho qualitativo, numa abordagem longitudinal, com a aplicação de um questionário para a coleta de dados, considerando uma amostra de alunos dos seis períodos do curso de pedagogia pertencentes aos 27 polos de apoio presencial da instituição selecionada (em São Paulo e outros estados do Brasil).

Os sujeitos da pesquisa foram 238 alunos deste curso, que aceitaram participar da pesquisa, espontaneamente, respondendo ao questionário que foi encaminhado no primeiro semestre de 2009. A amostra considerou alunos dos seis períodos do curso, o que totalizou 325 questionários encaminhados. Todos os alunos participantes assinaram o Termo de Consentimento Livre e Esclarecido, a partir da aprovação da realização da pesquisa, pelo Comitê de Ética da Instituição das pesquisadoras.

O questionário aplicado possui uma primeira parte com questões para a coleta de dados sobre o Perfil do Aluno e, uma segunda parte, com questões para o aluno informar as suas opiniões e percepções sobre o próprio curso. Os questionários, encaminhados pelo correio em maio de 2009, retornaram às pesquisadoras, também pelo correio, entre os meses de agosto e setembro de 2009. Com a tabulação das 
respostas, foi possível construir o Perfil dos Alunos e desenvolver uma análise tendo como referência a metodologia de análise de conteúdo proposta por Franco (2008), considerando as opiniões e percepções apresentadas sobre o próprio curso.

\section{OS RESULTADOS DA PESQUISA}

\section{Perfil dos Alunos}

A análise dos dados coletados através das respostas dos alunos possibilitou a organização de um perfil geral, em termos de informações sobre o período do curso em que se encontravam por ocasião da pesquisa e de qual região pertenciam e, um perfil mais específico, em termos de dados sócio-econômicos, como faixa etária, sexo, renda, etnia etc., que apresentamos a seguir.

No mapeamento acerca dos períodos em que os alunos se encontravam, na época da aplicação do questionário ( $1^{\mathrm{o}}$ semestre de 2009), a maioria freqüentava o $2^{\mathrm{O}}$ período ( 58 alunos), seguido pelos $4^{\mathrm{O}}$ período ( 49 alunos), $1^{\mathrm{o}}$ período ( 33 alunos), $6^{\mathrm{o}}$ período (30 alunos), $5^{\mathrm{o}}$ período ( 28 alunos), $3^{\mathrm{o}}$ período ( 25 alunos) e, 15 alunos, não declararam o período.

Observamos que os alunos pertencem a 23 dos 27 polos existentes na época da aplicação da pesquisa: Bertioga, Campinas, Ceres, Eldorado, Franca Guaianases, Guaratingetá, Guarulhos, Itanhaém, Itapeva, Lins, Londrina, Macaé, Mauá, Perus, Petrópolis, Porto Velho, Presidente Prudente, Ribeirão Preto, Santos, São José dos Campos, São José do Rio Preto e Vila Velha. Os polos não participantes (que não retornaram os questionários enviados) foram: Bauru, Brasília, Imperatriz e Vitória da Conquista.

Os dados sobre a idade apontam que a faixa etária da maioria dos alunos concentra-se entre 20 a 29 anos ( 81 alunos) e 30 a 39 anos (80 alunos). Comparamos estes dados com o "Perfil dos Alunos" organizado pela Instituição do curso, a partir da inscrição dos candidatos na época do vestibular, no $1^{\circ}$ semestre de 2009. O critério institucional é: menos de 16 anos, 17 anos, 18 anos, 19 anos, 20 a 23 anos, 24 a 29 anos e acima de 29 anos, indicando que a faixa etária predominante é acima de 29 anos $-54 \%$, seguido de 24 a 29 anos $-27 \%$.

Verificando também, os indicadores sobre a média de idade dos alunos em cursos a distância, no Anuário Brasileiro Estatístico de Educação Aberta a Distância (Sánchez, 2008, p. 54), temos o seguinte: 


\begin{abstract}
“Aidade médiaémaior do quena educação presencial.Équase desprezível o número de alunos com menos de 18 anos, enquanto o número de alunos com mais de 30 anos prevalece para 35,8 das instituições da amostra, ou para exatamente $50 \%$ das cem instituições que responderam a pergunta. Fica claro que um terço dos alunos a distância está na faixa etária entre 30 a 34 anos [...]".
\end{abstract}

Os dados confirmam que, de fato, há uma característica em relação à idade média de alunos que frequentam cursos a distância - são mais velhos do que os alunos dos cursos presenciais, com idade em torno dos 30 anos.

A maioria dos alunos é do sexo feminino (208 alunas), o que confirma a tendência evidenciada nas estatísticas acerca da inserção das mulheres na profissão docente. Considerando que o Curso de Pedagogia forma, prioritariamente, o docente para atuar na educação infantil e nas séries iniciais do ensino fundamental, um estudo recente de Gatti e Barreto (2009, p. 24) sobre a profissão docente, confirma ainda essa tendência.

\begin{abstract}
"No que tange ao sexo do grupo, como é de conhecimento, a categoria dos professores é majoritariamente feminina (segundo a Pnad 2006, 83,1\% versus $16,9 \%$ do sexo masculino), apresentando algumas variações internas conforme o nível de ensino. É assim que a quase totalidade dos docentes na educação infantil (98\%) é de mulheres, prosseguindo com uma taxa de $88,3 \%$ no ensino fundamental como um todo e atingindo aí $93 \%$ entre os professores de $1^{\mathrm{a}}$ a $4^{\mathrm{a}}$ séries com formação de nível superior".
\end{abstract}

Em relação à nacionalidade dos alunos, a maioria (231 alunos) declara ser brasileira. Sete alunos não declararam sua nacionalidade.

Sobre a etnia, 163 alunos declararam que são "brancos", seguidos por 54 alunos que se declararam "pardos", 17 "negros", 3 "amarelos" e 1 "indígena", e esses dados se confirmam também na pesquisa de Gatti e Barreto (2009, p. 24), já citada, como uma tendência para os que irão atuar na docência: "Em termos de raça/cor, a maioria $(61,3 \%)$ dos docentes se autoclassificou como brancos e 38,7\% como não brancos, conjunto em que predominam os pardos".

Consideramos importante analisarmos a etnia dos alunos tendo em vista os Indicadores Sociais do Brasil/2009 do IBGE - Instituto Brasileiro de Geografia e Estatística, que sinalizam que o maior nível de escolarização da população brasileira 
permanece, ainda, entre os "brancos" e, acrescentamos a isso, o fato de que a melhoria da renda financeira está diretamente relacionada à formação escolar.

\begin{abstract}
“Em 2008, dois terços dos jovens brancos e menos de um terço dos pretos e pardos cursavam o nível superior. $14,7 \%$ dos brancos e somente 4,7\% dos pretos e pardos adultos tinham superior completo em 2008. Entre o $1 \%$ com o maior rendimento familiar per capita na população brasileira, apenas $15 \%$ eram pretos ou pardos. Em 2008, no que diz respeito à média de anos de estudo da população de 15 anos e mais, as pessoas de cor branca apresentavam uma vantagem de quase dois anos (8.3 anos de estudos), em relação a pretos e pardos (6.7 e 6,5 anos), diferença que vem se mantendo constante ao longo dos anos. De 1998 a 2008, houve significativa melhora na distribuição da frequência por níveis de ensino entre a população de cor preta e parda. Entretanto, em 1998, um terço dos brancos jovens de 18 a 24 anos de idade já estava frequentando o ensino superior, contra 7,1\% dos pretos e pardos. Em 2008, os jovens brancos que freqüentava esse nível de ensino eram $60,3 \%$ do total, enquanto entre pretos e pardos o percentual era de 28,7\%" (BRASIL/IBGE, sem página).
\end{abstract}

Em que pese, ainda, as informações do Censo de 2010 no Brasil, que indicam que a maioria da população brasileira é de origem "branca" (49,7\%), seguida de "pardos" (42,6\%), "negros" (6,9\%), "amarelos" (0,5\%) e "indígenas" (o,3\%), a diferença entre a maioria de "brancos" em relação aos "pardos", é mínima, e fica evidente, nos dados do nosso estudo que, apesar da possibilidade de acesso que a modalidade a distância vem proporcionando, inclusive à população de baixa renda, a maioria dos alunos é formada por "brancos".

Sobre o estado civil, 152 alunos são casados, seguidos por 63 alunos que se declaram solteiros, 17 separados, 4 viúvos e 2 não declararam. Este dado, de maioria ser casada, pode até ser entendido como conseqüência da média da idade dos alunos.

Em relação à escolaridade dos pais, não são observadas grandes diferenças entre a escolaridade das mães e da dos pais, dos alunos. Os dados indicam que, a maioria, tem o ensino fundamental incompleto (séries iniciais - 107 mães e 116 pais) seguido pelo ensino fundamental completo (40 mães e 31 pais).

A renda familiar mensal da maioria dos alunos está na faixa de "03 a 06 salários mínimos” (99 alunos), seguida por “até 03 salários mínimos” (90 alunos), “de 07 a 
10 salários mínimos" (27 alunos), "acima de 10 salários mínimos" (17 alunos) e, 5 alunos, não declararam. Em que pese a pouca diferença entre os nossos indicadores e os indicadores dos dados estatísticos do Anuário Brasileiro Estatístico de Educação Aberta a Distância, que definem a faixa salarial "de 01 a 03 salários mínimos" e "de o3 a o5 salários mínimos”, os nossos dados são coincidentes com os do anuário, considerando-se os alunos de cursos de graduação a distância:

\begin{abstract}
"Do total da amostra, 29\% (ou 57,8\% dos que responderam à questão) afirmaram que seus alunos têm renda entre 1 a 3 salários mínimos, contra apenas $21 \%$ com renda superior a 3 salários mínimos. (...) os estudantes de cursos nos níveis de educação básica, técnica e EJA são majoritariamente mais pobres do que os que fazem cursos no nível de graduação e pós-graduação (credenciamento federal)" (Sánchez, 2008, p. 55).
\end{abstract}

A maioria dos alunos (184) declarou possuir computador em casa conectado à internet, 53 alunos declararam não possuir computador e um aluno não declarou. Esse dado chegou a surpreender, pois a informação dos professores tutores, que acompanham o curso, indicava dificuldades de alunos em realizarem as atividades complementares, de postarem as mesmas no AVA - Ambiente Virtual de Aprendizagem, ou mesmo de navegarem no ambiente, pela falta de conhecimento ou por não possuírem computadores. Parece que, de fato, esta dificuldade mencionada se refere a uma pequena parcela dos alunos e podemos inferir que tal fato esteja muito mais relacionado à falta de familiaridade com a Internet (em alguns casos) do que motivada por falta do equipamento, até porque, nos polos, há horários disponibilizados aos alunos que não possuem computadores em casa, para frequentarem os laboratórios.

Mas, não podemos deixar de atentar para o indicador de que 53 alunos não possuem computador em casa. Isso demonstra, infelizmente, que uma parcela significativa de alunos é afetada pela "exclusão digital" e, as discussões em torno desta questão, apontam para reflexões importantes sobre as consequências disto, como assinalam Sorj e Guedes (sem data, p. 2):

"A maneira pela qual a pobreza é definida e percebida depende do nível de desenvolvimento cultural / tecnológico / político de cada sociedade. A introdução de novos produtos que passam a ser indicativos de condição de vida "civilizada" (seja telefone, eletricidade, geladeira, rádio ou TV) aumenta o patamar de bens considerados necessários, abaixo do qual uma pessoa, ou família, é considerada pobre. Como o ciclo de acesso a 
novos produtos começa com os ricos e, posteriormente, se estende aos pobres, depois de um tempo mais ou menos longo (e o ciclo nem sempre se completa), a introdução de novos produtos essenciais aumenta a desigualdade. Os ricos são os primeiros a usufruir as vantagens do uso e/ou domínio dos novos produtos, no mercado de trabalho enquanto a sua carência aumenta as desvantagens dos grupos excluídos. Em ambos os casos, novos produtos das TICs - Tecnologias da Informação e Comunicação, aumentam, em princípio, a pobreza e a exclusão digital”.

Em relação à formação anterior, 192 alunos declararam que não possuem curso completo de graduação, seguido por 46 alunos que declararam que possuem curso de graduação completo. Os cursos/áreas dos cursos completos declarados são: Artes Plásticas, Contabilidade, Desenho Industrial, Direito, Educação Física, Engenharia de Materiais, Filosofia, Jornalismo, Fisioterapia, Fonoaudiologia, Geografia, História, Hotelaria, Inglês, Letras, Odontologia, Pedagogia, Prótese Dentária, Psicologia, Publicidade e Propaganda, Secretariado Executivo e Turismo. Muito provavelmente, são alunos que buscam na Pedagogia um aperfeiçoamento, ou atualização, para atuarem como docentes.

Da mesma forma, em relação a cursos de Pós-Graduação completo, 226 alunos declararam que não possuem e apenas 12 alunos declararam que possuem - os cursos realizados são de especialização/lato sensu: Administração, Psicossomática, Língua Espanhola, Marketing, Gestão Educacional, Direito do Trabalho, Psicoterapia, Psicopedagogia, Pedagogia Empresarial.

A maioria dos alunos trabalha (193 alunos), seguido por 44 alunos que declararam não estar trabalhando (1 aluno não respondeu esta questão).

Em relação à área de atuação, dos 193 alunos que declararam que trabalham, 125 atuam na área da educação (professores, setor administrativo, coordenação, outras funções pedagógicas), “outras áreas” - 55 alunos (militar, funcionalismo público, saúde, comércio, jurídica, administrativa, doméstica, sindicato, transporte) e, "não declararam", 13 alunos.

Sobre terem experiência como professores, 148 alunos declararam que a possuem, seguido por 88 alunos que não a possuem (2 alunos não responderam a questão).

Considerando os 148 alunos que declararam ter experiência como professores, há uma variação quanto ao nível de ensino (declarado por 94 alunos) - Educação 
Infantil (45 alunos); Ensino Fundamental (24 alunos); Ensino Médio (1 aluno); Ensino Superior (1 aluno); outros - não há especificação (23 alunos).

Os dados aqui apresentados, sobre o perfil dos alunos de um curso de Pedagogia a Distância, demonstram que alguns indicadores convergem para características já discutidas na área, ou seja, de que os alunos que freqüentam cursos de graduação a distância pertencem a uma faixa etária mais velha do que dos alunos dos cursos presenciais; que a maioria possui uma renda familiar baixa, são casados, possuem pais com escolaridade mínima e trabalham.

“(...) o estudante de EAD é marcadamente distinto do estudante presencial: Ele é em média mais velho, mais pobre, menos branco, majoritariamente casado, tem filhos, vem mais da escola pública, tem pais com escolaridade básica, trabalha e sustenta a família, tem menos acesso à internet, usa menos o computador (...)" (Sánchez, 2008, p. 1718).

Mas, observamos algumas distinções no perfil dos alunos. Em primeiro lugar, a maioria possui computador conectado à internet, e isso, por si só, demonstra que, apesar da baixa renda da maioria dos alunos, estão tendo acesso não só a um equipamento que até pouco tempo era um privilégio de poucos, mas também estão tendo acesso à formação superior, especialmente porque o valor das mensalidades dos cursos a distância são sempre inferiores ao valor, de um mesmo curso, oferecido na modalidade presencial.

E, aqui, comporta uma importante discussão proposta por Bohadana e Valle (2009, p. 552) que se refere à larga expansão da educação a distância no Brasil o que permitiu que a mesma.

“(...) passasse, de recurso marginal e pouco freqüente, a menina dos olhos das políticas públicas e das ações empresariais levadas a cabo na atualidade. Hoje, diferentemente do que ocorria há apenas uma década, não é mais possível desconsiderar o impacto que a introdução da $\mathrm{EAD}$ online causou e as transformações que certamente ainda ocasionará em nossas formas correntes de conceber e praticar a educação e a comunicação".

Mas não só isso, a questão maior se atrela aos desdobramentos desta expansão, que vem se expressando pela vertiginosa oferta de cursos na modalidade a distância, para atender não só as dificuldades de acesso ao ensino superior de uma parcela 
da população que até então se encontrava excluída (quer por questões financeiras, quer pela falta de tempo ou pela distância), mas principalmente pelo atendimento às "necessidades de mercado" e isso, sem dúvida, pode agravar as "desigualdades educacionais já produzidas a cada vez que se visou a uma rápida expansão de 'oportunidades' medidas em resultados estritamente quantitativos" (idem, p. 552). As autoras ainda propõem provocativas indagações que são importantes para as nossas reflexões.

“(...) a EAD on-line responde essencialmente à proposta de fazer mais para quem pode menos - e tão somente esse projeto de educar cada vez mais pessoas em menos tempo e a maior distância? Mas a que necessidades formativas deveria atender e a que clientela ser dirigida a EAD? Em que casos seria ela aplicável e em que casos deveria ser afastada como inadequada? Ou deveria essa modalidade ser entendida como uma indicação universal?” (Bohadana e Valle, 2009, p. 552).

Em segundo lugar, a maioria trabalha na área da educação; alguns já possuem uma graduação anterior com alguns casos também de cursos de especialização e estes indicadores nos permitem inferir que é possível a busca pelo curso de Pedagogia como uma formação continuada (e não somente como formação inicial), até pela expressa atuação na área da educação.

Do ponto de vista de se pensar o curso de Pedagogia enquanto atualização ou complementação profissional, acreditamos que esses dados apontam para uma importante contribuição formativa, de qualificação profissional. Mas, quando pensamos no curso de Pedagogia como formação inicial, sentimos uma grande preocupação, por conta de um fenômeno que nos inquieta, e que tem provocado perplexidade - a entrada de alunos semianalfabetos no ensino superior, por conta de uma formação anterior, inadequada. Segundo o INAF/2009 - Indicador de Analfabetismo Funcional:

"A maioria (54\%) dos brasileiros entre 15 e 64 anos que estudaram até a $4^{\mathrm{a}}$ série atinge no máximo o grau rudimentar de alfabetismo, ou seja, possuem no máximo a habilidade de localizar informações explícitas, em textos curtos ou efetuar operações matemáticas simples, mas não são capazes de compreender textos mais longos, localizar informações que exijam alguma inferência ou mesmo definir uma estratégia de cálculo para a resolução de problemas. E ainda mais grave: 10\% destes indivíduos podem ser considerados analfabetos absolutos em termos de habilidades de leitura/escrita, não conseguindo nem mesmo decodificar 


\author{
N. PANiCACCI; M. GeRAeS \\ Carrera de Pedagogía a Distancia: Obstáculos en la Proposición de la Carrera...
}

palavras e frases, ainda que em textos simples ou apresentam grandes dificuldades em lidar com números em situações do cotidiano, apesar de terem cursado de um a quatro anos do Ensino Fundamental. Dentre os que cursam ou cursaram da $5^{\mathrm{a}}$ a $8^{\mathrm{a}}$ série, apenas $15 \%$ podem ser considerados plenamente alfabetizados. Chama mais a atenção o fato de que $24 \%$ dos que completaram entre 5 e 8 séries do ensino fundamental ainda permaneçam no nível rudimentar, com sérias limitações tanto em termos de suas habilidades de leitura/escrita quanto em matemática. Somente 38\% dos que cursaram alguma série ou completaram o Ensino Médio atingem o nível Pleno de alfabetismo (esperado para 100\% deste grupo). Somente entre os que chegaram ao Ensino Superior é que prevalecem (68\%) os indivíduos com pleno domínio das habilidades de leitura/escrita e das habilidades matemáticas" (INAF, 2009, pp. 10-11).

Apesar da melhoria em relação a alguns indicadores, se comparados com os dos anos anteriores, o indicador não deixa claro se os sujeitos do ensino superior pertencem a cursos presenciais ou a distância. Talvez isso signifique alguma diferença, em nossa análise, tendo em vista o perfil dos alunos apresentado em nosso estudo, que coincide com outras pesquisas. É evidente a idade elevada dos alunos desta modalidade e, podemos inferir, que isso possa estar atrelado não só à opção pelo curso enquanto segunda graduação, por parte de alguns alunos mas, em relação a outros alunos, pela oportunidade de adentrarem a este nível de ensino enquanto formação inicial, o que significa que estes alunos permaneceram, um tempo, distantes dos bancos escolares e, talvez, possam apresentar dificuldades em relação à competência leitora e escritora, porque também somadas à má formação anterior, conforme apontada pelo INAF.

\title{
As análises sobre as opiniões e percepções dos alunos sobre o próprio curso
}

Consideramos os dados obtidos por meio do questionário respondido por 241 alunos. Para uma melhor visualização, optamos por apresentar questão por questão, em quadros, com a quantificação das respostas dadas pelos alunos, seguidas da análise. 
Questão 1) Terminarei o curso daqui a:

(a) um semestre -56 alunos;

(b) um ano - 30 alunos;

(c) um ano e meio - 56 alunos;

(d) dois anos -30 alunos;

(e) dois anos e meio - 66 alunos;

Não respondeu - 03 alunos.

Como se pode observar, a maioria dos alunos pertence a um grupo que já cursou mais da metade do curso, que é oferecido em três anos. Isso pode significar que as considerações realizadas são seguras, tendo em vista a familiaridade com os vários procedimentos do curso, pelo tempo que o estão freqüentando.

Questão 2) Como o curso é a distância, os encontros presenciais ocorrem uma vez por semana, o que considero:

(a) suficientes - 203 alunos;

(b) insuficientes -38 alunos.

A maioria dos alunos considera suficiente um encontro presencial, por semana, e isso nos parece que vai de encontro às discussões já realizadas, em outros estudos e pesquisas, que indicam que a flexibilidade do horário é uma forte justificativa para a opção por um curso a distância. Apenas para complementar, recorremos à pesquisa de Vianney (2006, p. 141), que investigou as Representações Sociais da Educação a Distância:

“(...) a representação social da educação a distância, para os 201 entrevistados do Grupo A, pode ser entendida como uma modalidade que facilita o estudo dos alunos pelas características de ser flexível na liberdade do horário para estudar, caracterizando-se por comodidade e rapidez, o que torna o acesso facilitado".

Mas, não podemos deixar de discutir sobre a questão da temporalidade dos cursos a distância, especialmente tendo como referência o estudo realizado por Oliveira (2008) e o que isto vem significando em termos da "racionalidade das atuais políticas educacionais brasileiras, com reflexos na Educação a Distância" (p. 
1). A autora considera que não é possível pensar em propostas de formação docente sem uma discussão acerca da autonomia dos formadores em relação ao tempo de aprendizagem e, mais, sobre a relação disto na definição de um tempo preciso e suficiente em que se esgotem os conteúdos de um determinado tema (conf. p. 10), e esse tempo é, normalmente, definido pela instituição que propõe os programas de formação docente a distância.

"Hoje em dia, o substrato econômico que constitui o modus operandi das tecnologias acaba por eliminar as distâncias e tornar o tempo instantâneo. Essa dupla equação acaba por embotar as consciências, pela saturação de informações, a serem decodificadas em curto espaço de tempo. Diante da alienação resultante da consciência embotada, a facilidade de manipular a população, a massificação. [...] como conceber programas de formação docente, nos quais os formadores não dispõem de autonomia sobre o tempo de aprendizagem, sobre o tempo destinado a cada um dos conceitos a serem trabalhados, ao longo das várias etapas que compõem um programa de formação docente online?” (pp. 7 e 10).

E a partir destas considerações, fica uma dúvida se, de fato, a avaliação positiva dos alunos acerca da suficiência de um contato semanal com um professor temático, signifique que o conteúdo a ser discutido e fundamentado em um determinado tema, ocorra de forma adequada para uma sólida formação dos alunos ou, salvo melhor juízo, se não estamos diante de uma avaliação positiva dos alunos por conta da zona de conforto em que se encontram, enquanto alunos que são, de um curso a distância flexível e cômodo em relação ao tempo do horário de estudos.

A seguir, quatro questões $(3,4,5$ e 6$)$ serão apresentadas agrupadas, para a análise, porque possuem proximidade em relação à temática que as circundam e que se refere aos procedimentos adotados no curso em relação à disponibilidade e proposição de materiais, organização dos estudos e ambiente virtual de aprendizagem:

Questão 3) Sobre os materiais disponibilizados aos alunos, há um Guia de Estudos com textos básicos sobre os Temas desenvolvidos, indicação de leituras de textos complementares, indicação de vídeos e filmes diversos, breezes e podcasts, e os considero:

(a) de qualidade - 223 alunos;

(b) com pouca qualidade - 18 alunos;

(c) sem qualidade - o. 
Questão 4) Sobre as teleaulas realizadas nos encontros presenciais, consideroas: (a) adequadas -158 alunos;

(b) parcialmente adequadas -80 alunos;

(c) inadequadas - 02 alunos;

Não respondeu - 01 aluno.

Questão 5) Sobre a organização dos estudos, toda semana recebemos um planejamento do professor que irá dar a teleaula daquela semana, com a solicitação de leituras e tarefas, o que considero:

(a) adequado - 209 alunos;

(b) parcialmente adequado - 31 alunos;

(c) inadequado - 01 aluno.

Questão 6) Sobre a plataforma Moodle utilizada no curso, onde todos os materiais são disponibilizados, enviamos e recebemos mensagens diversas e postamos nossos trabalhos, a considero:

(a) adequada -181 alunos;

(b) parcialmente adequada - 51 alunos;

(c) inadequada - 07 alunos;

Não respondeu - 02 alunos.

Como podemos observar, há um bom nível de aceitação, pelas considerações dos alunos, acerca da adequação dos materiais que o curso disponibiliza ou indica, das teleaulas ministradas, da proposta de planejamento semanal e da plataforma do ambiente virtual de aprendizagem.

Mas, não podemos deixar de acrescentar, na nossa análise, algumas discussões que se pautam no ânimo dos envolvidos com a educação a distância, pela "novidade" que a modalidade representa, e acabam por não perceberem, muitas vezes, que a "inovação pedagógica não é inovação tecnológica" (conf. Fino, sem data), e assistirmos a incoerência entre práticas pedagógicas propostas na educação a distância, inspiradas nas práticas pedagógicas presenciais: 
"Uma grande parte desses cursos é estruturada a partir de uma concepção tradicional de educação (muitas vezes velada sob uma roupagem mais avançada), em que o objetivo final do processo de aprendizagem é apenas a reprodução de um conhecimento já estabelecido, propiciando poucas condições efetivas para uma construção do conhecimento mais criativa, a ser realizada pelos sujeitos dessa prática educativa. Reproduz-se, dessa forma, um modelo pedagógico já saturado, impedindo a exploração dos potenciais trazidos pelas estruturas de comunicação em rede. Os cursos on-line tornam-se, assim, espelhos daquilo que há de pior no ensino presencial de hoje, com o agravante de estarem sendo apresentados para a população como uma das grandes inovações educacionais dos últimos tempos". (Nova e Alves, 2003, pp. 4-5).

Assim, necessitamos destas reflexões, não no sentido de negarmos a modalidade, ou só criticá-la, mas de colocarmos a mesma no lugar em que está atualmente, ou seja, num palco em evidência pelas mudanças de paradigmas que a mesma vem provocando (acerca da formação de professores, das relações sobre tempo-espaço x ensino-aprendizagem e etc.) e é preciso um tempo maior de investigações e de análises de resultados sobre a sua expansão para que a mesma possa atender as necessidades objetivas de uma formação qualificada, tendo em vista as potencialidades que as tecnologias da informação e comunicação, aliadas à proposição da educação a distância, podem promover.

Questão 7) A principal comunicação no curso, é com os professores-tutores, que acompanham as entregas das atividades ou tarefas que realizamos e esclarecem dúvidas, e considero esta comunicação:

(a) satisfatória - 164 alunos;

(b) pouco satisfatória - 63 alunos;

(c) insatisfatória - 13 alunos;

Não respondeu - 01 aluno.

Apesar da maioria (164 alunos) declarar satisfação em relação à comunicação com os professores tutores, observamos que 63 alunos a consideram "pouco satisfatória" e, essa questão, da comunicação/interação, tem estado em evidência em vários estudos já realizados. Bahia e Duran (2009, p. 75), numa pesquisa realizada sobre um mapeamento acerca da produção na área da educação a distância, enquanto formação inicial e continuada, afirmam que: 


\begin{abstract}
“A ênfase de alguns trabalhos em relação à interatividade, uma questão sempre presente em torno do ensino a distância, talvez ocorra devido às dúvidas e inquietações que cercam as relações, a comunicação e o diálogo entre o professor e os alunos e entre os próprios alunos em cursos a distância. Há muito pouco tempo, era comum constatarmos a perplexidade de alunos, em discussões informais sobre a EAD, que não entendiam ser possível uma relação pedagógica que não presencial, que não possibilitasse o "olho no olho", além de comentários sobre o distanciamento e a frieza que a educação a distância iria provocar na relação professor-aluno e alunos-alunos. E as pesquisas apontam, exatamente, para a importância do diálogo constante, aproximado, entre os sujeitos envolvidos, como auxiliar para a aprendizagem e para a participação dos alunos”.
\end{abstract}

Isso significa que, quer seja presencialmente, ou a distância, há uma expectativa de um relacionamento efetivo, e porque não afetivo, e constante entre os alunos e os professores, e não acreditamos que isso fosse diferente por conta de uma ou outra modalidade, ao contrário, porque há uma complexidade em torno das relações humanas (de ações, reações e emoções) que se soma a uma outra, que é a complexidade própria do contexto sócio-histórico em que se dão estas relações entre diferentes sujeitos sociais.

Questão 8) A avaliação é realizada por meio de um plano de avaliação que envolve: - questões de múltipla escolha sobre um Tema, realizada individualmente, - avaliação Modular realizada em grupos, - avaliação presencial final, realizada individualmente, e considero este plano:

(a) adequado - 190 alunos;

(b) parcialmente adequado - 38 alunos;

(c) inadequado - 09 alunos;

Não respondeu - 04 alunos.

Como já brevemente anunciado, a educação a distância buscou muitos referenciais nas experiências das práticas pedagógicas da educação presencial, e isso pode até parecer inevitável porque esta era a referência única de se fazer educação, antes da modalidade a distância, como a vemos hoje. Logo, podemos até entender como natural algumas adaptações de uma modalidade para a outra, especialmente em relação à avaliação, mas, isso só deve ser entendido assim, em se tratando do 
início da organização e proposição da modalidade, porque já existem alguns estudos e pesquisas que discutem a questão da avaliação na modalidade a distância.

\begin{abstract}
"A avaliação da aprendizagem na sala de aula online requer rupturas com o modelo tradicional de avaliação historicamente cristalizado na sala de aula presencial. Se o professor não quiser subutilizar as potencialidades próprias do digital online, ou se não quiser repetir os mesmos equívocos da avaliação tradicional, terá de buscar novas posturas, novas estratégias de engajamento no contexto mesmo da docência e da aprendizagem e aí redimensionar suas práticas de avaliar a aprendizagem e sua própria atuação" (Silva, 2006, p. 23).
\end{abstract}

Nada de muito novo, até porque o autor retoma a indiscutível colaboração de Hoffmann e seus estudos e pesquisas que marcaram significativamente as discussões, na época, sobre avaliação, e Silva (2006, p. 23), complementa.

\begin{abstract}
"As conclusões de sua pesquisa (de Hoffmann) sugerem fortemente a opção pela 'avaliação mediadora', como orientação teórico-prática para superar o modelo tradicional de avaliação na perspectiva de uma 'prática de avaliação construtivista e libertadora'. Essa orientação se sustenta nos fundamentos autonomia, dialógica, participação e colaboração para superar o modelo baseado na arbitrariedade da avaliação baseada em provas, conceitos, boletim, recuperação e reprovação".
\end{abstract}

Os fundamentos propostos por Hoffmann, segundo Silva (2006, p. 24), comungam atualmente com "a perspectiva da interatividade sustentando as comunidades de aprendizagem em redes online que valorizam autonomia, dialógica, participação e colaboração" e, a partir disso é possível pensarmos em propostas avaliativas com uma maior sintonia, e adaptadas, às exigências atuais de acompanhamento e avaliação das práticas avaliativas a distância.

\footnotetext{
"Precisamos nos preparar para a aprendizagem e para a avaliação interativa na sala de aula online. Podemos disponibilizar informações, propostas de trabalho, links para sites temáticos, bibliografia, imagens, música, filmes, além do planejamento do curso especificando objetivos e conteúdos programáticos, e aí situar o processo de avaliação. No ambiente digital online podemos promover e incentivar a troca de experiências, a ajuda mútua, a participação em debates online e a construção coletiva do conhecimento e da própria avaliação" (Silva, 2006, p. 35).
} 
Algumas discussões sobre a avaliação na educação a distância (Silva, 2006; Primo, 2006; Bruno e Moraes, 2006), evidenciam a valorização de práticas que estimulem a autoria dos alunos, a autonomia e a cooperação; e o processo avaliativo, exatamente porque processo, precisa ser permanente, e isso significa um diferencial na modalidade a distância, pela possibilidade de retomada das atividades realizadas nos ambientes virtuais de aprendizagem.

"Nos ambientes online, tudo o que foi co-construído fica registrado, permitindo que revisitemos arquivos, textos, idéias, sentimentos, argumentos etc. a qualquer momento. Em tal contexto, o registro das informações e das construções de professor e alunos torna-se forte aliado nesse processo" (Bruno e Moraes, 2006, p. 64).

Tendo em vista a proximidade da essência das duas próximas questões (9 e 10), que se referem à aceitação e/ou preconceito sobre a modalidade a distância, optamos por apresentá-las conjuntamente para a realização da análise.

Questão 9) Quando comento que faço um curso a distância, percebo que as pessoas reagem de forma:

(a) positiva - 100 alunos;

(b) negativa -137 alunos;

Não respondeu - 04 alunos.

Questão 10) De um modo geral:

sinto (x) - 152 alunos;

não sinto (x) - 78 alunos;

Não respondeu -11 alunos.

- que as pessoas têm preconceito com cursos a distância.

Apesar da subjetividade implícita na formulação das duas questões - são os alunos respondendo sobre "como percebem a reação das pessoas" e sobre "como percebem o preconceito das pessoas", emergem sentimentos negativos, percebidos pelos alunos - de não aceitação e de preconceito - e isso parece denotar que a modalidade seja considerada de menor prestígio. 
Entendemos que as críticas sobre os cursos a distância de formação inicial de professores são importantes -como exemplo, o expressivo manifesto da ANFOPE Associação Nacional pela Formação de Profissionais da Educação-, através de um Boletim em 2007, já citado, que apresenta uma crítica sobre a proliferação de cursos a distância de má qualidade, que aligeirizam e barateiam a formação. A entidade posiciona-se em defesa da ideia de que:

“[...] os programas de educação a distância para a formação de professores deverão, sempre que possível, ser suplementares e antecedidos pela formação inicial presencial, além de estar vinculados a instituições que tenham experiência comprovada em formação inicial de professores e no uso de novas tecnologias de comunicação e informação" (ANFOPE, 2007, sem página).

Diante disto e, passados três anos deste manifesto, a mesma questão é retomada na CONAE - Conferência Nacional de Educação (2010, p. 82), que recomenda em seu documento final.

"A formação e a valorização dos/das profissionais do magistério devem
contemplar aspectos estruturais, particularmente, e superar as soluções
emergenciais, tais como: cursos de graduação (formação inicial) a
distância; cursos de duração reduzida; contratação de profissionais
liberais como docentes; aproveitamento de estudantes de licenciatura
como docentes; e uso complementar de telessalas. E extinguir, ainda,
todas as políticas aligeiradas de formação por parte de "empresas", por
apresentarem conteúdos desvinculados dos interesses da educação
pública, bem como superar políticas de formação que têm como diretriz
o parâmetro operacional do mercado e visam a um novo tecnicismo,
separando concepção e execução na prática educacional".

Consideramos também a recente pesquisa realizada por Gatti e Barreto (2009, p. 116) onde as autoras apontam para uma questão importante sobre a modalidade:

"A grande inquietação da comunidade de educadores diante desse quadro é que a inserção, nos moldes propostos, de uma modalidade de formação docente que é oferecida ainda de maneira mais precária que a dos cursos presenciais, em vez de contribuir para a solução da crise de formação de professores, poderá tornar mais frágeis os processos de formação docente e desestabilizar uma larga experiência acumulada de formação que, a despeito das críticas que lhe são devidas, requer alternativas que contribuam para fortalecê-la e consolidá-la”. 


\author{
N. PANiCACCI; M. GERAES \\ Carrera de Pedagogía a Distancia: Obstáculos en la Proposición de la Carrera...
}

As críticas expressas sobre a formação inicial ocorrer em cursos a distância, se mantém, e isso significa que é importante também considerar o necessário desenvolvimento de mecanismos de acompanhamento e avaliação destes cursos, porque é clara e legítima a preocupação de todos com a qualidade da formação inicial de professores, como também, se a mesma deve ocorrer na modalidade a distância. Mas é importante observar que:

"Com todos os defeitos que possam ter os processos formativos (ou a certificação) providos por cursos de licenciatura a distância, não se pode imputar aos licenciados nesta modalidade as razões da baixa qualidade de ensino na educação básica deste País. O baixo nível de qualidade da educação básica brasileira tem razões conjunturais que ultrapassam, em muito, a suposta baixa qualificação dos egressos de cursos de licenciatura a distância” (Sommer, 2010, p. 27).

\title{
CONSIDERAÇÕES FINAIS
}

Éinegável a expansão da modalidade a distância no nosso cenário educacional, em particular no ensino superior, e isso se justifica pela proposição oficial da modalidade por meio de um discurso em defesa da democratização do acesso ao ensino superior, comportando um forte apelo pela inclusão de grande parte da população brasileira que estava excluída deste nível de ensino mas que, segundo Scheibe (2006, p. 200).

"Faz-se necessário, nesse sentido, reagir face à qualificação precária que ocorre como consequiência dos inúmeros projetos de formação inicial cuja ênfase está na certificação de profissionais em serviço, realizados à distância ou de forma semipresencial, em todo o país. É importante, portanto, refletir sobre as implicações teórico-práticas das atuais políticas de formação inicial para professores, em cursos de graduação a distância, implementados a partir da nova LDBEN/96 - Lei de Diretrizes de Bases da Educação Nacional, e que formam hoje número expressivo de professores de maneira mais ou menos emergencial”.

Assim, não podemos deixar de trazer também para esta discussão, as reflexões e críticas de Lima (2004, p. 1) a respeito da "proposta do Governo Lula da Silva de utilização da educação a distância, como estratégia de 'democratização' do acesso às instituições públicas de ensino superior". Esta autora acredita que "a lógica que atravessa e constitui a proposta de ampliação do acesso à educação via educação a distância, omite uma estratégia de aprofundamento do processo de privatização da educação pública brasileira” (idem, p. 1) e, somamos a isso, as preocupações 
que indicam também o atendimento desmedido dos interesses do capitalismo (Bohadana e Valle, 2009; Oliveira, 2008). Isso significa que é preciso atentar para os mecanismos oficiais de expansão da modalidade e de acompanhamento e avaliação dos cursos, porque já estamos assistindo à corrida desenfreada de proposição da modalidade e isso se reflete nas avaliações e pesquisas realizadas que apontam para o sucateamento e aligeiramento da formação, neste nível de ensino. (Gatti e Barreto, 2009; CONAE, 2010; Nova e Alves, 2003).

"O movimento inicial da educação a distância, o de proporcionar formação regular e continuada aos professores em exercício (os professores leigos), é repleto de mérito e, porque não dizer, de êxito. Não se pode falar o mesmo, entretanto, do que veio depois, quando os cursos de formação de professores passaram a disputar os alunos dos cursos presenciais, substituindo a sala de aula pela formação em trânsito, descolada dos espaços tradicionais de ensino-aprendizagem" (Giolo, 2008, sem página).

Muitas experiências que observamos na modalidade a distância ainda são marcadas por referenciais das práticas presenciais - e não poderia ser ao contrário - porque impregnadas há muito nos processos de formação e atuação de professores e no cotidiano escolar. Seria possível imaginarmos experiências desenvolvidas completamente inovadoras e diferentes de tudo o que vivemos e conhecemos? Parece ingênuo demais acreditar nesta possibilidade. Logo, as tentativas, as idas-e-vindas, as coerências-incoerências das práticas em EAD que estão sendo organizadas, devem ser entendidas como parte de um processo de profundas mudanças na relação pedagógica, processo que pretende se firmar e se consolidar no meio educacional.

Lidamos também com a não-familiaridade dos recursos midiáticos e das tecnologias da informação e da comunicação em rede, além dos diferentes e diversificados ambientes virtuais. A apropriação, o domínio e a familiaridade com todos esses recursos e as possibilidades que apresentam, se configuram como um desafio de inclusão de todos.

“As TICs e o ciberespaço, como um novo espaço pedagógico, oferecem grandes possibilidades e desafios para a atividade cognitiva, afetiva e social dos alunos e dos professores de todos os níveis de ensino, dojardimde-infância à universidade. [...] Mais do que o caráter instrumental e restrito do uso das tecnologias para a realização de tarefas em sala de aula, é chegada a hora de alargar os horizontes da escola e de seus participantes, ou seja, de todos. O que se propõe para a educação de 
cada cidadão dessa nova sociedade - e, portanto, de todos, cada aluno e cada professor - é não apenas formar o consumidor e usuário, mas criar condições para garantir o surgimento de produtores e desenvolvedores de tecnologias. Mais ainda, que não aprendam apenas a usar e produzir, mas também a interagir e participar socialmente e, desse modo, integrarse em novas comunidades e criar novos significados para a educação num espaço muito mais alargado" (Kenski, 2007, pp. 66-67).

As práticas avaliativas também passam por muita reflexão e revisão a partir do que conhecíamos mais tradicionalmente na educação presencial e das discussões mais recentes, na educação a distância, ou seja, estamos repensando as mesmas tendo como referência a interação e o envolvimento dos alunos diante dos instrumentos que lhes são apresentados. Mas não tem sido tarefa fácil, porque parece que alguns alunos, e também alguns professores, possuem posturas impregnadas de ideias retrógradas e equivocadas em relação à avaliação, muito provavelmente porque se submeteram a instrumentos fortemente marcados por uma concepção excludente.

A educação a distância, como formação inicial e/ou como formação continuada de professores, é ainda um desafio para a construção de uma nova profissionalidade dos docentes e a incorporação com êxito da EAD em cursos de formação de professores, exige o desenvolvimento de inovações tecnológicas e está relacionada a atitudes e expectativas tanto dos professores formadores como também dos alunos em formação.

Alvariño (2004, p. 180) apresenta uma reflexão importante ao concluir seu relato sobre uma experiência com a formação a distância de 15 mil professores, no Chile:

\begin{abstract}
"As estratégias didáticas da educaçãoa distânciatradicional(estabelecidas em função das limitações comunicativas da tecnologia disponível em seu momento e centradas nos materiais de ensino e em uma comunicação assimétrica entre o professor e cada um dos estudantes) deixaram de ter sentido com a introdução de novas tecnologias da informação. Estão sendo incorporadas rapidamente novas perspectivas didáticas, como a aprendizagem colaborativa, possibilitada pela comunicação simétrica, multidirecional, multiformato, em um ambiente rico em recursos formativos (materiais e pessoais) e pelos meios abertos das redes informáticas e, especialmente, da internet”.
\end{abstract}

Se por um lado, observamos esforços de algumas instituições e seus profissionais, engajados na proposição de cursos a distância comprometidos com a qualidade da 
formação de futuros professores, por outro lado lidamos com as contradições entre a legislação que legitima a formação inicial a distância com os manifestos e críticas sobre ela - e isso significa que as desconfianças, as inseguranças e os preconceitos se instalam.

Acreditamos que estes sentimentos poderão ser superados a partir da continuidade deste debate e, especialmente, de pesquisas com os egressos que possam comprovar a competência da formação a distância, mas que, no contexto brasileiro, estão apenas se iniciando ${ }^{3}$. E, mais do que isto, é preciso também que os cursos a distância continuem sendo alvo de intensa avaliação pelos órgãos governamentais, para que seja superada também a idéia da modalidade estar atrelada a um aligeiramento e barateamento da formação.

\footnotetext{
"Reconhecendo as inúmeras vantagens da educação a distância, continuo preocupado com os modelos da maioria dos cursos focados, tanto a distância como presenciais, mais no conteúdo do que na pesquisa; na leitura pronta mais do que na investigação e em projetos. $\mathrm{O}$ ensino superior, tanto no presencial como no a distância, reproduz, ainda, um modelo inadequado para a sociedade da informação e do conhecimento, onde nos encontramos. Com as tecnologias cada vez mais rápidas e integradas, o conceito de presença e distância se altera profundamente e as formas de ensinar e aprender também. Estamos caminhando para uma aproximação sem precedentes entre os cursos presenciais (cada vez mais semipresenciais) e os a distância. Os presenciais começam a ter disciplinas parcialmente a distância e outras totalmente a distância. E os mesmos professores que estão no presencial-virtual começam a atuar também na educação a distância. Teremos inúmeras possibilidades de aprendizagem que combinarão o melhor do presencial (quando possível) com as facilidades do virtual” (Moran, sem data).
}

Não podemos finalizar nossas discussões sem considerar a experiência brasileira com a educação a distância no ensino superior, considerada ainda inicial, diante das inúmeras experiências de vanguarda de países como EUA, Canadá, Inglaterra, Portugal, Espanha, Austrália, México, Argentina, Venezuela, África do Sul (só para citarmos alguns exemplos) que, com certeza, enfrentaram, e/ou ainda enfrentam, dificuldades e problemas que se assemelham aos aqui expressos nesta pesquisa. O que fica claro é a importância da divulgação dos avanços na área, que podem e devem servir como referenciais para a consolidação de propostas mais acertadas para a modalidade a distância. 
Nossa intenção, com o estudo proposto, não era a de esgotar esta temática, pois acreditamos que as questões aqui colocadas possam ser motivo para outras reflexões e estudos - mas, uma coisa é certa, a educação a distância vem possibilitando um novo jeito de ser professor e de ser aluno, porque a modalidade requer fazeres diferenciados e que se configuram a partir de posturas e comportamentos necessários, como autonomia, liberdade, parceria e responsabilidade.

\section{NOTAS}

1 Implantado em 2005 pelo Ministério da Educação/Brasil, o Sistema UAB tem por objetivo democratizar, expandir e interiorizar a oferta de ensino superior público e gratuito no país. Com a missão fundamental de colaborar com o processo de formação inicial e continuada de professores para a educação básica, até 2013 o sistema ampliará sua rede de cooperação para atender 800 mil alunos/ano. [en línea] Disponible en: http://www.uab.capes.gov.br/images/stories/downloads/Catalogo/apresentao.pdf, (consulta 2011, 10 de maio).

2 O termo pardo é um termo oficial brasileiro formalmente utilizado para descrever alguém de origem mestiça. Noutros países em que se utiliza a língua portuguesa, usam-se com o mesmo significado os termos mulato ou mestiço. De acordo com o Instituto Brasileiro de Geografia e Estatística, o grupo pardo é um dos cinco grupos de "Cor ou Raça" que compõem a população brasileira, junto com brancos, pretos, amarelos e indígenas. Existem terminologias tradicionais usadas no Brasil para vários tipos de pardos, essas terminologias são as seguintes: mulatos para descendentes de brancos e pretos; caboclos e mamelucos para descendentes de brancos e indígenas; cafuzos para descendentes de pretos e indígenas; curiosamente, parece não haver uma terminologia além de pardo para definir alguém que seja descendente de brancos, índios e pretos simultaneamente. [en línea] Disponible en: http://pt.wikipedia.org/ wiki/Pardos (consulta 2011, 10 de maio).

3 Os estudos encontrados sobre pesquisas com egressos de Cursos de Pedagogia a distância, referem-se a: "avaliações sobre o curso"; "se cumpriram o objetivo de auxílio às práticas pedagógicas"; "se auxiliaram na construção da autonomia profissional"; etc. Não encontramos "estudos comparativos" entre egressos do curso nas modalidades a distância e presencial, que pudessem aprofundar as discussões sobre a construção e aquisição de competências pedagógicas "para" e "no" exercício profissional.

\section{REFERÊNCIAS BIBLIOGRÁFICAS}

Alvariño, C. (2004). A formação de professores à distância via internet. In: Tedesco, J. C. (Org.). Educação e novas tecnologias: esperança ou incerteza? Tradução de Claudia Berliner e Silvana C. Leite. São Paulo: Cortez; Buenos Aires:
Instituto Internacional de Planeamiento de La Educacion; Brasília: UNESCO, (165-181).

ANFOPE (2007). Associação Nacional pela Formação de Profissionais da Educação, Boletim 2007. [en línea] Disponible en: 
http://www.lite.fae.unicamp.br/anfope/ novo/html/boletim outubro o07.html (consulta 2011, 10 de maio).

Barreto, R. G.; Guimarães, G. C.; Magalhães, L. K. C.; Leher, E. M. T. (2006). As tecnologias da informação e da comunicação na formação de professores. Revista Brasileira de Educação, 11 (31), ANPED, (31-42).

Bahia, N.P.; Duran, M.C.G.(2009). Formação de Professores em cursos a distância: um inclusão excludente? Revista Educação e Linguagem / Programa de PósGraduação em Educação. Universidade Metodista de São Paulo, 19, São Bernardo do Campo: SP: Metodista, (52-79).

Bohadana, E.; Valle, L. (2009). O quem da educação a distância. Revista Brasileira de Educação - ANPED, 14 (42), set./ dez., (551-564).

BRASIL. IBGE (2009). Instituto Brasileiro de Geografia e Estatística. Síntese dos Indicadores Sociais 2009. Ministério do Planejamento, Orçamento e Gestão. [en línea] Disponible en: http:// www.ibge.gov.br/home/presidencia/ noticias/noticia visualiza.php?id $\underline{\text { noticia=1476\&id pagina }=1}$ - (consulta 2011, 10 de maio).

BRASIL (MEC). CONAE (2010). Conferência Nacional de Educação. Brasília, 2010. Documento Final. [en línea] Disponible en: http://conae.mec.gov.br/index. php?option $=$ com content\&view $=$ articl e\&id=360: documento-final\&catid $=38$ : documentos\&Itemid $=59 \quad-\quad$ (consulta 2011, 10 de maio).

Bruno, A. R.; Moraes, M. C. (2006) O enfoque da complexidade e dos aspectos afetivo-emocionais na avaliação da aprendizagem em ambientes online. In: Silva, M.; Santos, E. (Orgs.). Avaliação da aprendizagem em educação online. São Paulo: Edições Loyola, (51-66).

Duran, M. C. G. (2008). Tecnologias, novas tecnologias e educação: um mapeamento da produção acadêmica sobre o tema.
Cadernos de Educação - Reflexões e Debates, UMESP. São Bernardo do Campo, 14, (38-52).

Fino, C. N. (sem data). Inovação pedagógica: significado e campo (de investigação). III Colóquio do Centro de Investigação em Educação da Universidade da Madeira/ Portugal. [en línea] Disponible en: http:// www3.uma.pt/carlosfino/publicacoes/ Inovacao Pedadogica Significado \%20e Campo.pdf - (consulta 2011, 10 de maio).

Franco, M. L. P. B. (2008) Análise de conteúdo. $3^{\text {a }}$ ed., Brasília: Liber Livro Editora.

Gatti, B. A. (2008). Análise das políticas públicas para formação continuada no Brasil, na última década. Revista Brasileira de Educação - ANPED, 13 (37), (57-70).

Gatti, B. A.; Barreto, E. S. (2009). Professores do Brasil: impasses e desafios. Brasília: UNESCO.

Giolo, J. (2008). A educação a distância e a formação de professores. Educação \& Sociedade, 29 (105), SP/Campinas.

INAF Brasil (2009). Indicador de Analfabetismo Funcional. Ação Educativa e Instituto Paulo Montenegro. [en línea] Disponible en: http://www. ipm.org.br/download/inaf brasil2009 relatorio divulgacao final.pdf (consulta 2011, 10 de maio).

Kenski, V. M. (2007). Educação e tecnologias - o novo ritmo da informação. $2^{\mathrm{a}}$ ed., Campinas/SP: Papirus.

Lima, K. R. (2004). Reforma da educação superior do Governo Lula e educação a distância: democratização ou subordinação das instituições de ensino superior à ordem do capital? [en línea] Disponible en: http://www.anped.org. br/reunioes/27/gt11/t119.pdf - (consulta 2011, 10 de maio).

Moran, J. M. (sem data). Avaliação do ensino superior a distância no Brasil. [en línea] Disponible en: http://www.eca.usp.br/ 
prof/moran/avaliacao.htm - (consulta 2011, 10 de maio).

Nova, C.; Alves, L. (2003). Educação a distância: limites e possibilidades. [en línea] Disponible en: http://www.lynn. pro.br/pdf/livro ead.pdf - (consulta 2011, 10 de maio).

Oliveira, L. M. P. (2008). A problemática do tempo nos programas de formação docente online. [en línea] Disponible en: http://www.anped.org.br/reunioes/ 31ra/1trabalho/GT16-3962--Int.pdf (consulta 2011, 10 de maio).

Primo, A. (2006). Avaliação em processos de educação problematizadora online. In: Silva, M.; Santos, E. (Orgs.). Avaliação da aprendizagem em educação online. São Paulo: Edições Loyola, 37-49).

Sanchez, F. (coord.). (2008). Anuário Brasileiro Estatístico de Educação Aberta e a Distância - 2008. $4^{\mathrm{a}}$ ed., São Paulo: Instituto Monitor.

Scheibe, L. (2006). Formação de professores: dilemas da formação inicial a distância. Educere Et Educare. Revista de Educação da UNIOESTE - Universidade Estadual do Oeste do Paraná, 1(2), (199212).

Silva, M. (2006). O fundamento comunicacional da avaliação da aprendizagem na sala de aula online. In: Silva, M.; Santos, E. (Orgs.). Avaliação da aprendizagem em educação online. São Paulo: Edições Loyola, ( 23-36).

Sommer, L. H. (2010). Formação inicial de professores a distância: questões para debate. Em Aberto, Brasília, 23 (84), (1730).

Sorj, B.; Guedes, L. E. (sem data). Exclusão digital: problemas conceituais, evidências empíricas e políticas públicas. [en línea] Disponible en: http://www.centroedelstein.org.br/pdf/ exclusaodigital problemasconceituais. pdf (consulta 2011, 10 de maio).

Valente, J. A.; Almeida, M. E. B. (Org.) (2007). Formação de educadores a distância e integração de mídias. São Paulo: Avercamp.

Vianney, J. (2006). As representações sociais da educação a distância: uma investigação junto a alunos do ensino superior a distância e a alunos do ensino superior presencial. Tese de Doutorado, Universidade Federal de Santa Catarina (Programa de Pós-Graduação Interdisciplinar em Ciências Humanas), Florianópolis.

\section{PERFIL ACADÊMICO E PROFISSIONAL DAS AUTORAS}

Norinês Panicacci Bahia. Possui graduação em Pedagogia, Mestrado em Educação e Doutorado em Educação, pela Pontifícia Universidade Católica de São Paulo. Atualmente é Docente Pesquisadora do Programa de Pós-Graduação: Mestrado em Educação e Professora do Curso de Pedagogia Presencial e a Distância da UMESP - Universidade Metodista de São Paulo. Coordenadora do Grupo de Estudos e Pesquisas sobre Educação a Distância. Atua no Ensino Superior há 15 anos. 
Marília Claret Geraes Duran. Possui graduação em Pedagogia (FEUSP) Mestrado e Doutorado em Educação pela Pontifícia Universidade Católica de São Paulo. Atualmente é professor titular da Universidade Metodista de São Paulo, como professora permanente do Programa de Pós-Graduação em Educação (Mestrado). Coordena o Núcleo de Estudos e Pesquisas sobre Formação de Educadores (FormAção), inscrito no CNPq e associado ao (CIERS-Ed/FCC), onde desenvolveu Estágio Pós-Doutoral ( 2009).

\section{DIRECCIÓN DE LAS AUTORAS}

Norinês Panicacci Bahia:

Rua Tupi, 634, ap. 51 - São Paulo/SP - Brasil

- Cep. 01233-00o

Marília Claret Geraes Duran

Rua Dr. Veiga Filho, 371, apto. 2B - São

Paulo/SP - Brasil - Cep. 01229001

Fecha de recepción del artículo: 24/02/11

Fecha de aceptación del artículo: 01/06/11

\section{Como citar este artículo:}

Panicacci Bahia, N.; Geraes Duran, M. (2011). Carrera de pedagogía a distancia: obstáculos en la proposición de la carrera como formación inicial. RIED. Revista Iberoamericana de Educación a Distancia, volumen 14, nº 2, pp. 121-148. 